\title{
MENERAWANG MASA LALU DI ERA DIGITAL: FILM SEJARAH VIS A VIS HISTORIOGRAFI
}

\author{
Luqman Abdul Hakim
}

Guru Sejarah SMA Muhammadiyah 3 Jakarta. Email: lqmnhkim@gmail.com

\section{ABSTRACT}

In recent years historical film production or historical films - Historical Film, Historical Movie, Historical Cinema - have become increasingly massive in Indonesia. In its development, historical films in Indonesia are a massive medium to present a past that deserves to be remembered as a collective memory of society. Since the reform era, dozens of historical film titles have been produced and colouring the Indonesian film industry. As a result, many historical films have become references and reference sources for the community to find information about the past. It becomes reasonable to see the development of multimedia-based information technology (audiovisual) which has encouraged the emergence of post-literacy phenomena. In historical studies, historical films can be studied as a thematic study as well as in a methodological realm. As a thematic study, historical films are mental products (mentifact) and social products (sociofact) of society in a certain space of time. Whereas in the methodological realm, historical films can be explored through debates about historical sources or as narratives and representations of the past presented through film media. The study of historical films as a study of history is still a rare and less desirable subject for historians in Indonesia. This paper utilizes literature studies to answer some of the research problems posed. Literature studies of sources related to historical film studies are the focus of the researchers. In addition, a deeper understanding of the development of historical films in Indonesia is also a concern to uncover the souls of the times that surround historical film production. This study concludes that the existence of historical films in the present is a challenge for historians to face the era of openness and variety of media that presents information about the past.

Kata Kunci: Historical Film, Post-Literacy, and Methodology

\section{PENDAHULUAN}

September 2017 menjadi bulan polemik di Indonesia berkat sebuah rencana Panglima TNI, Gatot Nurmantyo, yang hendak memutarkan kembali film Pengkhianatan G30S/PKI. Rencana tersebut, yang diliput dan menghiasi headline media massa selama berhari-hari bertujuan untuk mengenalkan sejarah Partai Komunis Indonesia sebagai dalang pembunuhan Jenderal TNI AD pada malam 1 Oktober 1965 kepada generasi muda (Kompas.com, 18 September 2017). Polemik yang menyeruak disebabkan oleh perdebatan tentang keabsahan informasi sejarah yang terkandung dalam film tersebut. Media massa banyak meliput pandangan dari 
petinggi politik, ketua organisasi masyarakat, pakar film, dan masyarakat umum tentang ketepatan informasi sejarah dalam film Pengkhianatan G30S/PKI. Beberapa menjawab dengan tegas, bahwa film tersebut sangat representatif dan menyajikan sejarah yang 'benar'. Sebagaian lain berpendapat bahwa film tersebut adalah film propaganda, atau hanya merupakan salah satu sumber informasi saja selain bukubuku dan artikel ilmiah lain tentang sejarah 1965. Namun, perdebatan itu malah ditutup oleh statement Wakil Presiden Jusuf Kalla agar perdebatan tentang pemutaran film G30S/PKI tidak diteruskan dan mengajak semua pihak mengesampingkan hal tersebut (Kompas.com, 4 Oktober 2017).

Belakangan ini menyajikan informasi sejarah melalui film kembali menjadi hal yang masif dan mewarnai belantika perfilman Indonesia. Jika dihitung sejak pergantian rezim politik 1998, munculnya film Gie (2005) adalah tonggak awal tersebut, hingga hari ini puluhan judul film bertema sejarah telah diproduksi setiap tahun dan tayang di layar lebar, antara lain Merah Putih (2009), Merah Putih 2: Darah Garuda (2010), Sang Pencerah (2010), Hati Merdeka (2011), Sang Penari (2011), Soegija (2012), Habibie E Ainun (2012), Sang Kiai (2013), Soekarno (2013), Tjokroaminoto (2015), Kartini (2016), dan Wage (2017). Produksi film sejarah umumnya mendapat dukungan dari instansi pemerintah atau keluarga para tokoh yang ingin kisah hidupnya diangkat ke layar lebar.

Meskipun produksi film sejarah bukanlah hal baru dalam perfilman Indonesia, belum banyak kajian ilmiah dari studi sejarah tertarik untuk membahas perihal tersebut. Pertanyaan-pertanyaan mendasar seperti sumber, fakta, interpretasi, dan penyajian masa lalu melalui media film tidak banyak mengundang perdebatan dalam studi sejarah. Beberapa penelitian sejarah yang bersinggungan dengan Film Sejarah lebih menempatkannya sebagai sebuah produk sosial maupun produk mental dari suatu zaman, seperti penelitian Katherine McGregor, Ketika Sejarah Berseragam: Membongkar Ideologi Militer dalam Menyusun Sejarah Indonesia (2008) atau Khrisna Sen, Kuasa dalam Sinema: Negara, Masyarakat, dan Sinema Orde Baru (2009).

Keberadaan film sejarah sendiri bukanlah sesuatu yang lepas dari perdebatan yang umumnya selalu dianggap tidak mampu menyajikan informasi sejarah secara tepat. Film sejarah, oleh beberapa sejarawan, dituduh mendramatisasi dan membuat distorsi terhadap masa lampau. Perdebatan tentang film sejarah berputar di permasalahan akurasi data sejarah dari film sejarah atau permasalahan film sebagai medium yang mendramatisir masa lalu sehingga mendistorsikan makna dari masa lalu yang ditampilkan.

Makalah ini berusaha untuk menunjukkan pentingnya mendalami film sejarah dari sudut pandang studi ilmu sejarah. Pendalaman atas metodologi dari keilmuan sejarah diharapkan mampu untuk mengikuti perkembangan zaman dan menghadapi keberadaan film sejarah yang hari ini diamini sebagai salah satu media untuk menerawang masa lalu. Apakah film sejarah hanya dapat dikaji sebagai produk sosial maupun produk mental dari sebuah konteks zaman di masa lampau? Ataukah film sejarah dapat menjadi sumber maupun cara baru dalam menyajikan masa lalu? Pertanyaan lain yang kurang lebih penting adalah melihat kemungkinan tersebut dalam konteks Indonesia yang menganggap film sejarah adalah medium yang masif untuk menyampaikan masa lalu yang pantas diingat oleh bangsa Indonesia (Film Nasional). Untuk itu, pembahasan dalam makalah ini akan dibagi menjadi beberapa 
bagian. Pertama, pembahasan tentang definisi film sejarah dan penjabaran tentang konteks zaman digital dimana muncul fenomena post-literasi. Kedua, pembahasan tentang perkembangan film sejarah di Indonesia, dan terakhir bagaimana metodologi sejarah memberi ruang dalam mengkaji film sejarah.

\section{Film Sejarah di Tengah Era Digital}

Semenjak ditemukannya alat untuk merekam gambar bergerak, film telah berhasil memberi dampak yang luas bagi masyarakat. Sebagai teknologi yang dihasilkan beriringan dengan berbagai teknologi lain pasca Revolusi Industri, film telah menjadi perangkat teknologi yang menjadi basis industri besar, serta bentuk hiburan baru dan media artistik baru (Kristin Thompson, 2003: 13). Kemampuan film dalam menampilkan realitas secara mimetik dan hampir sempurna telah berhasil membangun nuansa yang baru bagi seni pertunjukan dan hiburan. Tak hanya menampilkan drama, film juga menampilkan representasi masa lalu ke dalam gambar bergerak. Namun, film yang menampilkan masa lalu sejak lama telah memicu debat publik seperti yang awalnya menjadi eksperimen dari D. W. Griffith dalam film The Birth of a Nation (1915) yang terkenal (Robert Burgoyne, 2008: 1).

Perdebatan publik ini juga sampai di kalangan sejarawan ketika salah satu sejarawan terkemuka, Louis Gottschalk, mengemukakan pendapatnya tentang film sejarah, "Tidak ada gambaran tentang sejarah yang harus ditawarkan kepada publik sampai seorang sejarawan terkemuka memiliki kesempatan untuk mengkritik dan merevisinya" (Marcia Landy, ed., 2001: 50). Pernyataan itu merupakan sikap Gottschalk menanggapi popularitas Film Hollywood pada masa itu yang turut menjadikan sejarah sebagai objek yang ditampilkan dalam sinema. Sikap Gottschalk diikuti hampir oleh banyak sejarawan setelahnya dalam memandang sinis film sejarah.

Hingga hari ini perdebatan tersebut masih menjadi hal yang hangat dan memicu kalangan akademis untuk mulai mendefinisikan tentang film sejarah. Piere Sorlin mendefinisikan Film sejarah sebagai gambar bergerak yang mampu menghubungkan masa lalu yang ditampilkan di layar dengan pengetahuan masyarakat tentang masa lalu. Menurutnya film sejarah bukan sebuah disiplin yang harus dijelaskan sebagai salah satu jenis film, melainkan film yang mampu mengantarkan penonton pada sebuah pengetahuan masa lalu-peristiwa, tanggaltanggal penting, tokoh-tokoh - sebagai warisan kebudayaan yang dimiliki oleh suatu komunitas (Landy, ed., 2001: 37). Selain itu, Robert Rosenstone juga memberikan pandangannya sendiri tentang definisi film sejarah. Menurutnya istilah tersebut berlaku untuk film yang secara sadar membangun latar di masa lalu atau film yang dengan sengaja berangkat untuk menggambarkan masa lalu (Robert Rosenstone, ed., 2013: 1). Definisi film sejarah yang lebih luas adalah bahwa film tersebut didasarkan pada masa lalu yang telah didokumentasikan, dan sebuah proyek untuk menciptakan dunia masa lalu yang dapat diketahui dan ditampilkan ke layar. (Robert Burgoyne, 2008: 2)

Penjabaran tersebut terasa masih sangat umum dan luas sehingga beberapa akademisi lain berusaha menjelaskan film sejarah dengan menempatkannya sebagai bagian dari genre film. Natalie Davies, menjelaskan film sejarah sebagai bagian dari feature film (film cerita) yang plot utamanya berdasarkan peristiwa historis yang 
sebenarnya, atau dimana plot imajiner terbentang sedemikian rupa sehingga peristiwa historis yang sebenarnya sangat penting dan menjadi unsur yang intrinsik pada cerita (Natalie Davies, 2000: 50). Burgoyne membagi film sejarah, khususnya sebagai sebuah genre film sejarah Amerika yang di produksi oleh Hollywood dan membaginya lagi ke dalam beberapa cabang sub-genre yaitu film perang, epik, biografi, film topikal, dan perkembangan bentuk kontemporer baru seperti film metahistoris (Burgoyne, 2008: 2). Sedangkan Vincent J. Binsson dalam tesisnya yang menyatakan, "Historical films are not categorized based on how they use history", dan dia sendiri membuat skema untuk mengkategorisasikan film sejarah berdasarkan kadar ke-fiksi-an hingga kefaktual-an dari representasi peristiwa masa lampau yang dihadirkan oleh film. Dimulai dengan kadar fiksi yang paling tinggi yaitu Historical entertaintment film, period film, faction film, dan terakhir dengan kadar faktual tertinggi adalah biopic/evenpic film (Vincent J. Binsson, 2010: 2).

Namun, apa yang membuat gairah akademisi untuk mendefinisikan film sejarah adalah sebuah fenomena zaman yang baru dimana teknologi informasi berbasis digital dan audiovisual berkembang pesat. Munculnya zaman audiovisual dan fenomena post-literasi telah menjadi sebuah kenyataan dimana masyarakat memperoleh ataupun mencari sumber informasi dan pengetahuan melalui media digital berbasis audiovisual. Masyarakat post-literasi adalah hipotetis tentang keadaan masyarakat dimana teknologi telah memungkinkan kita untuk mentransfer informasi secara lebih efisien dan efektif daripada membaca dan menulis (beyondliteracy.com, 15 November 2012). Fenomena ini, menggoyahkan posisi literasi dalam arti sumber pengetahuan tertulis ke arah sumber pengetahuan berbasis digital dan audiovisual.

Kondisi demikian tentu juga menggoyahkan posisi historiografi sebagai bentuk penyajian tertulis dalam disiplin ilmu sejarah. Di Amerika Serikat misalnya, sebuah projek yang didanai oleh National Endownment for the Humanities terbit sebagai buku yang berjudul Image as Artifact: The Historycal Analysis of Film and Televeision, terpicu oleh kenyataan bahwa kebanyakan orang Amerika mempelajari sejarah melalui film dan televisi. (Binsson, 2010: 27). Ada pula kegundahan dari sejarawan yang menyadari bahwa:

"Today the chief source of historical knowledge for the bulk of the populationoutside of the much-despised textbook - must surely be the visual media, a set of institutions which lies almost wholly outside the control of those of us who devote our lives to history." (Rosenstone, 1986: 3)

Film sejarah hari ini telah digunakan baik sebagai propaganda, pendidikan maupun hiburan. Film sejarah telah mendapat perhatian untuk ditinjau latar belakang produksi (dimensi sosial, politik, ekonomi), bagaimana ia diperlakukan sebagai teks yang diharapkan menghasilkan penonton yang penuh perhatian, simpatik, dan aktif dan untuk meningkatkan kesadaran politik tentang masa lalu, serta bagaimana film sejarah mampu menjadi simbol pengikat bagi sebuah bangsa (Rosenstone, 2013: 4-5). Dalam dunia pendidikan, film sejarah telah mendapatkan tempat yang penting dalam pembelajaran sejarah sebagai alat bantu pembelajaran sejarah. Film sejarah mampu membuat sejarah menjadi nyata, menarik dan seperti hidup, serta membantu guru sejarah dalam menyampaikan materi-materi sejarah. Film sejarah juga mampu secara 
lebih baik mengendapkan pengetahuan siswa tentang masa lalu karena secara maksimal mengoptimalkan kemampuan panca indera (S.K. Kochhar, 2008: 212).

Melihat fakta-fakta bahwa film sejarah telah memainkan peran penting dalam kehidupan masyarakat hari ini, perdebatan yang mengklaim bahwa film sejarah mendistorsi dan mendramatisir masa lalu menjadi tidak relevan. Para akademisi sejarah sudah perlu lebih lanjut menyelidiki bagaimana film sejarah dapat menjadi sumber dan bentuk penyajian baru selain historiografi. Film sejarah tidak harus dibandingkan sepadan dengan historiografi (sejarah sebagai sebuah hasil dari riset sejarawan), melainkan dengan melihatnya sebagai vision of the past (Landy, ed.,2001: 62). Historiografi memiliki keunggulan dalam memberikan penjelasan (eksplanasi) tentang proses serta kausalitas sebuah peristiwa, tetapi film sejarah unggul dalam hal merepresentasikan dan menghadirkan citra tentang masa lalu. Melalui film sejarah, penonton mampu lebih mudah membayangkan masa lalu, perangkat audio dan visualisasi yang bergerak membuat masa lalu itu sendiri seolah benar-benar hadir di layar.

\section{Perkembangan Film Sejarah di Indonesia}

Dalam perkembangannya di Indonesia, film memang telah diproduksi sejak masa pemerintah kolonial Hindia Belanda. Mulai munculnya bioskop yang saat itu dibangun sebagai akibat dari modernisasi, mendorong pula produksi film-film yang mengambil latar cerita kehidupan di Hindia Belanda. Film cerita pertama yang diproduksi pada masa itu adalah Loetoeng Kasaroeng, yang diangkat dari sebuah dongeng masyarakat Sunda (Misbach Yusa Biran, 2009: 60).

Meski telah ada produksi film sejak tahun 1926, film sejarah di Indonesia baru muncul sejak tahun 1950-an. Film Darah dan Doa (1950) sering disebut sebagai film sejarah pertama yang diproduksi di Indonesia. Mengisahkan perjalanan panjang (long march) prajurit divisi Siliwangi pada 4 Februari 1949, yang diperintahkan kembali ke pangkalan semula, dari Yogyakarya ke Jawa Barat setelah Yogyakarta diserang dan diduduki pasukan Belanda (Laela Chudori, 2015: 2; Budi Irawanto: 101). Setelah itu, film-film karya Usmar Ismail sering diidentikan dengan genre film sejarah, meskipun pada saat itu istilah Film Nasional (Film Perjuangan) lebih dikenal. Sebab di Indonesia, film sejarah selalu diidentikan dengan film-film yang mengangkat tema-tema perjuangan bangsa Indonesia di masa lalu, ataupun tokoh-tokoh yang dikenal sebagai pahlawan. Pada 1950-an sampai 1980-an, film-film berlatar belakang sejarah hanya mengambil perang Kemerdekaan atau nama-nama besar sebagai latar belakang (Laela, 2015: 2). Film sejarah di Indonesia dimaknai sebagai sebuah medium massif untuk menghadirkan masa lalu yang ideal bagi bangsa Indonesia serta dapat meningkatkan dan mengkampanyekan nasionalisme.

Pemaknaan film sejarah sebagai medium masif untuk menghadirkan masa lalu yang ideal tidak terlepas dari proses munculnya produksi film Indonesia. Adanya semangat nasionalisme pasca kemerdekaan yang mendorong terciptanya produk budaya baru, membuat film digunakan oleh seniman nasional sebagai medium yang paling efektif untuk mewujudkan dan menyebarluaskan gagasan budaya nasional. Pengalaman penjajahan Jepang yang menjadikan film sebagai alat propaganda turut mempengarui munculnya pandangan tersebut (Hikmat Darmawan, 2017: 59). Pada 
masa awal ini pula muncul dikotomi yang diperkenalkan Salim Said sebagai film idealis dengan film komersil (Darmawan, 2017: 62). Film sejarah dan film nasional pun masuk ke dalam kategori film idealis, dimana upaya menyampaikan sesuatu dari pembuat film ke khalayak adalah yang utama, dan bukan keuntungan atau popularitas. Munculnya istilah film idealis menurut Khrisna Sen merupakan pola yang umum dalam Sinema Ketiga (film-film yang diproduksi oleh dunia ketiga) yang membedakannya dari film Hollywood, yaitu bahwa pesan sosial-budaya serta politik diungkapkan secara eksplisit dalam teks film (Sen, 2009: 2).

Film sejarah di Indonesia makin marak ketika rezim Orde Baru (1968-1998) bergulir. Pada masa ini film-film sejarah tidak sekedar mengkampanyakan nasionalisme atau perjuangan bangsa, tetapi juga menjadi medium ideologi militer. Dari sejumlah film yang bertutur tentang revolusi Indonesia misalnya, hampir seluruh pusat penceritaan adalah militer. (Irawanto, 1999: 105). Beberapa film sejarah bahkan dibuat atau disponsori oleh militer seperti Mereka Kembali (1972) dan Bandung Lautan Api (1975) yang disponsori Kodam Siliwangi. Sejarah di masa orde baru dengan masa sebelumnya memang memiliki kesamaan-keduanya menggunakan film sebagai medium yang masif atau alat komunikasi sosial yang efektif untuk mempropagandakan nasionalisme. Hal yang membedakan tentu adalah karakter rezim itu sendiri. Jika nasionalisme di masa sebelumnya terbuka atas perbedaan ideologi, kultural dan dipadukan menjadi sesuatu yang baru, nasionalisme di masa Orde Baru malah merupakan sesuatu hal yang monolitik, absolut dan abstrak (Darmawan, 2017: 110). Tidak ada ruang untuk memperdebatkan nasionalisme di masa Orde Baru selain Nasionalisme yang dipropagandakan oleh Negara. Disini dapat dilihat bagaimana pemaknaan atas film sejarah tidak terlepas bahwa film sejarah sendiri merupakan produk sosial dan kultural dari suatu zaman.

Akibat pemaknaan atas nasionalisme yang monolitik dan absolu tmembuat produksi film sejarah lebih sekedar alat untuk mengkampanyekan 'nasionalisme' ketimbang memperhatikan 'keakuratan sejarah'. Hal ini terjadi pada saat rencana produksi film Perang Padri (1981) ditolak oleh Direktorat Film. Alasan penolakan tersebut adalah bahwa film bertema sejarah ditujukkan untuk penonton masa kini sehingga harus mempertimbangkan sikap yang berlaku sekarang dan mencakup misi ke depan (Sen, 2009: 135). Padahal berdasarkan laporan dari Departemen Pendidikan dan Kebudayaan film tersebut tidak melenceng dari fakta-fakta sejarah dan antropologi, sebab naskah yang dilihat pada saat itu hanya tidak mempertimbangkan segi keakuratan sejarah melainkan pertimbangan politis saja (Sen, 2009: 137-138). Film Perang Padri secara ironis ditolak sebab berusaha menampakkan peristiwa sejarah yang dianggap bertentangan dengan kepentingan politik dan nasionalisme yang dimaknai di zaman Orde Baru.

Produksi film sejarah di Indonesia nampaknya pun hingga hari ini masih hanya berkutat pada narasi-narasi yang mengingatkan identik dengan film nasional, meskipun mulai muncul juga film-film berlatar sejarah yang tujuan akhirnya bukan sekedar mengkampanyekan masa lalu yang 'pantas diingat' seperti Sang Penari (2011) dan Soegija (2012). Selebihnya, tokoh-tokoh besar, pahlawan nasional dan peristiwaperistiwa perjuangan bangsa yang monumental melawan penjajahan masih menjadi tema-tema yang mendominasi film sejarah di Indonesia. Bahkan setelah rezim orde 
baru, narasi militer dalam film sejarah masih merupakan tema yang diminati untuk diproduksi.

Film sejarah sebagai alat kampanye bagi nasionalisme bukan hampa masalah, melainkan-seperti yang terjadi pada film Perang Padri-dapat membuat upaya menghadirkan narasi-narasi yang lain sesuai fakta-fakta yang ditemukan tentang masa lalu menjadi tidak mungkin hadir dalam layar. Selain itu, secara komersil Laela Chudori menyebut film sejarah di Indonesia memiliki beberapa masalah yang membuatnya menjadi tidak menorah popularitas di masyarakat, yaitu: intervensi yang melingkupi produksi film sejarah; pengetahuan sejarah yang umumnya belum berkembang di masyarakat sebab kualitas pendidikan sejarah yang masih rendah; lisensi poetika yang digunakan oleh para pembuat film yang kurang meyakinkan; dan pendekatan kronologis dalam produksi film sejarah yang membuat film sejarah seolah memiliki unsur didaktik serta dalam beberapa kasus film biopic lebih menyerupai $C V$ yang divisualisasikan (Laela, 2015: 7-8).

Mendefiniskan film sejarah atau menjadikan definisi film sejarah sebagai acuan untuk mengkaji film di Indonesia mungkin akan menjadi sesuatu hal yang problematik. Karena secara umum, film sejarah dimaknai sebagai alat legitimasi bagi bangsa dan negara untuk mempromosikan kepentingan politik nasional kepada masyarakat. Seperti yang diungkapkan oleh Heidder, meskipun banyak film sejarah diproduksi di Indonesia, lebih baik menganggap semua itu sebagai sebuah pernyataan sejarah (historical statement) ketimbang sebuah genre yang khusus (Irawanto, 1999: 98).

\section{Mendudukkan Film Sejarah dalam Studi Ilmu Sejarah}

Dalam menghadapi zaman baru, sejarawan perlu merumuskan cara pandang yang baru untuk menentukan posisi film sejarah sebagai sumber pengetahuan sejarah. Kita perlu menyikapi keberadaan film sejarah dengan tidak membandingkannya sepadan dengan historiografi (sejarah sebagai sebuah hasil dari riset sejarawan) dan dengan melihat film sejarah sebagai vision of the past. Rosenstone menjelaskan perbedaan film sejarah dengan historiografi dengan membandingkan keduanya berdasarkan media yang digunakan.

"The word works differently from the image. The word can provide vast amounts of data in a small space. The word can generalize, talk of great abstractions like revolution, evolution, and progress, and make us believe that these things exist (...)Film, with its need for a specific image, cannot make general statements about revolution or progress . Instead, film must summarize, synthesize, generalize, symbolize-in images." (Landy, 2001: 62)
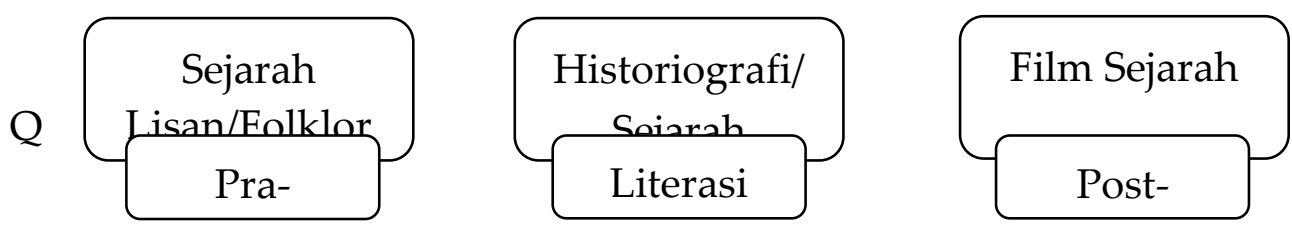

Film sejarah tidak dapat dinilai seperti penilaian kita terhadap historiografi. Posisi film sejarah di era post-literasi patutnya dapat disejajarkan dengan sejarah lisan (oral history) yang merupakan sumber pengetahuan tentang masa lalu yang 
diproduksi oleh masyarakat pra-literasi. Keberadaan film sejarah sebagai media untuk menghadirkan informasi tentang masa lampau sejatinya memiliki fungsi dan kemampuan khusus, dan harus dibedakan dengan sejarah tertulis, terlepas dari motif-politik, ekonomi, maupun konteks sosial-yang melatarbelakangi motif pembuatan film sejarah yang tentu saja pasti juga melekat dalam apa yang dihasilkan sejarawan dalam historiografi.

Persepsi ini juga perlu mendorong film sejarah sebagai sebuah cara berpikir sejarah yang baru. Seperti yang dikatakan oleh Rosenstone, film-film sejarah merupakan semacam sejarah dengan bahasa istimewanya sendiri dan kebenarannya sendiri. Dan mungkin, para ilmuwan tidak dapat menangani film sejarah sebagai semacam sejarah sampai kita menemukan persepsi dan cara yang tepat untuk membicarakan film serta mengevaluasi kontribusi mereka terhadap pemahaman kita tentang masa lalu (Rosenstone, ed., 2013: 84). Untuk memahami sejarah dalam film sejarah, kita perlu menganalisisnya sebagai representasi visual, dan segi dramatis yang melibatkan hubungan masa lalu, sekarang, dan masa depan dengan segala momen, kejadian, tokoh, kepercayaan, serta ideologi yang melingkupinya. Film sejarah harus dkaji dengan mengabungkan analisis sejarah tertulis dengan analisis genre studi film (Rosenstone, ed., 2013: 85).

Gagasan Rosesnstone agaknya begitu dipengaruhi oleh konsep yang diajukan oleh Hayden White tentang Historiophoty (representasi sejarah dan pemikiran kita tentang masa lalu dalam gambar visual dan wacana film). White juga bersikeras bahwa representasi peristiwa sejarah, dan tokoh dalam citra visual mengandaikan penguasaan leksikon, tata bahasa, dan sintaksis yang sangat berbeda dari yang biasa digunakan untuk menafsirkan representasi dalam wacana verbal. Film sejarah dan berbagai sumber visual adalah sebuah wacana yang dengan sendirinya dapat memberi tahu kita referensi berbeda dari apa yang bisa disampaikan dalam wacana verbal, yang hanya bisa diceritakan melalui gambar visual (Hayden White, 1988: 1193).

Bagi keduanya, bukan tidak mungkin film sejarah menjadi sebuah sumber bagi sejarah. Hal yang diperlukan bagi sejarawan adalah merumuskan bagaimana memperlakukan film sejarah sebagai sumber. Analisis representasi terhadap film sejarah memerlukan ilmu bantu dari simbol-simbol yang ditampilkan oleh gambar bergerak. Perangkat-perangkat analisis dari kajian film juga diperlukan untuk menganalisis film sejarah sebagai sumber. Salah satu yang diajukan oleh Rosenstone adalah mengenai genre theory. Vincent J. Binsson mengaplikasikannya dengan membuat skema sub-genre film sejarah (historical entertainment film, period film, faction film, dan biopicleventpic). Vincent membuat kategorisasi sebagai sub-genre dalam film sejarah untuk dapat memudahkan orang-orang dalam menilai kadar kefaktualan masa lampau yang ditampilkan oleh film sejarah (Binsson, 2010: 40). Dalam Historical entertaintment, setting sejarah hanya bertujuan sebagai unsur entertaintment, dengan tujuan sebagai hiburan. Begitu pula dalam sub-genre Period Film-yang hanya mengambil periode sejarah yang faktual dan menempatkan karakter fiksi di dalam periode tersebut dengan tujuan untuk mendramatisasi peristiwa di masa lampau. Vincent dengan tegas menyatakan dalam kedua sub-genre film sejarah ini bahwa kita tidak dapat mengkritisi atau mengharapkan film ini menghadirkan masa lampau yang detail dan spesifik. Sedangkan untuk faction film serta biopiclevenpic film, disinilah 
biasanya terdapat perdebatan mengenai apakah masa lampau yang dihadirkan benarbenar sesuai dengan apa yang terjadi secara detail dan spesifik.

John O'Connor dalam bukunya, Teaching History with Film and Televeision, menawarkan sebuah cara bagi sejarawan untuk memanfaatkan film sebagai artefak, dan memberi panduan untuk menganalisis film sejarah dalam dua tahap - pertama: mengumpulkan informasi dari konten film, serta meninjau produksi dan resepsi dari film sebagai dokumen; dan kedua memetakan empat kerangka untuk penyelidikan sejarah dalam film. Empat kerangka kerja tersebut adalah The Moving Image as Evidence for Social and Cultural History, Moving-Image Documents as Representations of History, Actuality Footage as Evidence for Social and Cultural History, dan The History of the Moving Image as Industry and Art Form (John O'Connor, 1987: 5).

Selain perdebatan tentang bagaimana film sejarah mampu menjadi sumber bagi studi sejarah, hal lain yang dikaji oleh beberapa akademisi adalah bagaimana film sejarah dapat menjadi media baru untuk menyajikan informasi tentang masa lalu. Menurut Connor, sejarawan serta guru sejarah dalam konteks masyarakat yang terbuka dan demokratis, punya tanggung jawab kepada publik dan murid-muridnya untuk memudahkan mereka terhubung dengan peristiwa di masa lalu. Mereka juga harus membekali masyarakat suatu keterampilan kritis yang diperlukan untuk menilai serta menyajikan masa lalu (Connor, 1987: 3).

Pandangan yang diajukan Connor dekat dengan sebuah kajian baru dalam sejarah, yang dikenal sebagai sejarah publik (public history). Sejarah publik adalah sebuah pendekatan yang menawarkan kemungkinan bagi keterlibatan masyarakat dalam sebuah kebudayaan tertentu untuk berperan dalam membuat sejarah. Robert Archibald menegaskan bahwa, sejarah dimiliki oleh orang-orang yang masa lalunya mampu tergambarkan dalam sebuah narasi, yang membuat mereka terhubung dengan ingatan serta identitas mereka (Hilda Kean, ed., 2013: xv). Munculnya bidang sejarah publik dikarenakan adanya pandangan bahwa profesi sejarawan dan sejarah yang dihasilkannya tidak terikat langsung kepada publik. Publik dalam pekerjaan sejarawan akademis bersifat pasif sebagai objek. Semangat dalam sejarah public adalah tentang bagaimana menempatkan masa lalu bagi kepentingan masa sekarang. Sejarah publik menentang rekonstruksi resmi yang ada tentang masa lalu, dan mendorong setiap individu untuk memahami dan menafsirkan masa lalu untuk diri mereka sendiri dengan memberi makna bagi mereka sendiri (Hilda, ed., 2013: 9).

Film sejarah dalam hubungannya dengan sejarah publik dijembatani oleh definisi Piere Sorlin tentang film sejarah sebagai gambar bergerak yang mampu menghubungkan masa lalu yang ditampilkan di layar dengan pengetahuan masyarakat tentang masa lalu. Apalagi film dalam masyarakat yang terbuka tidak selalu dimaknai sebagai sebuah upaya komunikasi massal dan bertendensi sebagai alat propaganda, melainkan sebagai sebuah refleksi dari kondisi psikologis, hasrat, serta aspirasi dari masyarakat (Robert C. Allen, 1985:153). Dalam konteks film sebagai industri, film yang meraih keuntungan secara komersil adalah film yang mampu menampilkan keinginan, hasrat serta aspirasi masyarakat. Konten film sejarah yang terikat oleh ingatan masa lalu dari publik, bisa dikatakan adalah sebuah bentuk ideal jika merunut definisi Sorlin tentang film sejarah. Artinya, penyajian informasi masa lalu melalui film, bukan merupakan penolakan atau sesuatu yang akan membahayakan karya-karya dari sejarawan akademis. Munculnya tren penyajian 
sejarah melalui film adalah sebuah upaya dari masyarakat untuk memaknai masa lalu mereka sendiri, tentang kebudayaan maupun identitas mereka, yang mungkin terlewat dalam berbagai buku sejarah yang dihasilkan oleh sejarawan.

\section{KESIMPULAN}

Ariel Heryanto dalam bukunya, Identitas dan Kenikmatan: Politik Budaya Layar di Indonesia, memberi penjelasan tentang karakter masyarakat Indonesia yang ia sebut sebagai masyarakat yang berkiblat pada komunikasi lisan. Bentuk komunikasi ini menekankan pada keberadaan lawan bicara; ungkapan diri melalui kata-kata yang dituturkan dan bahasa tubuh dalam interaksi yang 'seketika' (Ariel Heryanto, 2015: 282). Hal ini menyebabkan orang Indonesia lebih mudah dalam menerima pesona dari gambar bergerak dan lebih tanggap secara kreatif terhadap apa yang tawarkan oleh kamera video, ketimbang kata-kata tertulis atau program komputer pengolah kata (Heryanto, 2015: 134). Dalam buku tersebut, Ariel juga menunjukkan bagaimana di Indonesia peran film dan hubungannya dengan penyampaian informasi sejarah merupakan sesuatu yang telah teruji, utamanya selama rezim Orde Baru berlangsung.

Seperti yang sudah disampaikan sebelumnya, produksi film sejarah adalah hal yang sudah lama berkembang di Indonesia, dan memperoleh pemaknaannya sendiri yang identik dengan Film Idealis, Film Perjuangan, dan Film Nasional. Sumber referensi dari film sejarah adalah tentu saja, narasi sejarah yang resmi dan yang diproduksi oleh negara. Hanya sedikit film sejarah yang mampu menghadirkan narasi sejarah alternatif, yang menurut Laela Chudori adalah salah satu masalah dalam produksi film sejarah di Indonesia (Laela, 2015: 7). Ketiadaan narasi sejarah alternatif sangat mungkin disebabkan oleh karena historiografi belum menjadi tradisi yang kuat dan mengakar dalam masyarakat Indonesia, serta karena proses pengajaran sejarah di sekolah yang tidak mampu mendorong masyarakat untuk menghadirkan narasi alternatif tentang masa lalu (Laela, 2015: 6; Heryanto, 2015:135).

Membayangkan bagaimana masyarakat Indonesia memperlakukan film sejarah, baik sebagai sumber maupun sebagai cara baru dalam menyajikan masa lalu, tidak mungkin tanpa melibatkan peran sejarawan. Peran sejarawan hari ini dibutuhkan untuk menjelaskan bagaimana mendudukkan film sejarah sebagai sumber pengetahuan, serta tanpa dapat dipungkiri, sebagai sumber inspirasi bagi produksi film sejarah. Ketiadaan narasi alternatif juga dimungkinkan karena hasil penelitian para sejarawan di Indonesia masih belum diakses secara meluas bagi masyarakat. Melihat bahwa film sejarah sebagai salah satu alternatif dalam menyajikan narasi masa lalu, keterlibatan sejarawan dalam bidang ini, seperti yang mungkin kita lihat dalam produksi film Tjokroaminoto, atau ke depannya dengan semakin banyaknya hasil kajian mengenai resepsi penonton terhadap film sejarah, perlu banyak dikembangkan. Tentu saja, bahwa tugas utama sejarawan adalah mendekati dan menghadirkan konstruksi terhadap masa lalu, tetapi tugas itu tidak dapat terlepas dari kebutuhan masa kini tentang bagaimana masa lalu dihadirkan dan dapat secara luas diakses oleh masyarakat. 


\section{DAFTAR PUSTAKA}

Allen, Robert C. \& Gomery, Douglas. "Film History: Theory and Practice”. McGraw-Hill, Inc. 1985.

Bisson, Vincent J. "Historical Film Reception: An Ethnographic Focus Beyond Entertainment". Tesis untuk gelar Master of Arts, Universitas of Oregon pada bulan Juni 2010

Burgoyne, Robert. "The Hollywood Historical Film”. Blackwell Publishing. 2008.

Chudori, Laela. "Dari Gie hingga Tjokroaminoto: Sebuah Diskusi tentang Film Biopic". Makalah yang disampaikan dalam diskusi, Film Sejarah di Indonesia, di Serambi Salihara, 8 Juli 2015.

Darmawan, Hikmat (ed.) "Merayakan Film Nasional". Direktorat Sejarah, Direktorat Jenderal Kebudayaan, Kementerian Pendidikan dan Kebudayaan Republik Indonesia. 2017

Davies, Natalie. "Slaves on Screen: Film and Historical Vision". Cambridge: Harvard University Press. 2000

Heryanto, Ariel. "Identitas dan Kenikmatan: Politik Budaya Layar Indonesia". Jakarta: Kepustakaan Populer Gramedia. 2015

Irawanto, Budi. "Film, Ideologi, dan Militer: Hegemoni Militer dalam Sinema Indonesia". Yogyakarta: Media Pressindo. 1999

Kean, Hilda \& Martin, Paul (ed.) "The Public History Reader". New York: Routledge. 2013

Kochhar, S.K. "Teaching History: Pembelajaran Sejarah". Jakarta: Grasindo. 2008

Landy, Marcia (ed.) "The Historical Film: History and Memory in Media". New Brunswick, New Jersey: Rutgers University Press. 2001

O'Connor, John E. "Teaching History with Film and Television". American Historical Association. National Endowment for the Humanities (NFAH), Washington, D.C. 1987.

Rosenstone, Robert A. \& Parvulescu, Constantine (ed.) "A Companion to the Historical Film". Wiley-Blackwell. 2013

Rosenstone, Robert A. "History in Image/History in Words: Reflections on the Possibility of Really Putting History on Film". Humanities Working Paper 121. Division of The Humanities and Social Sciences, California Institute of Technology. Desember 1986.

Sen, Krishna. "Kuasa dalam Sinema: Negara, Masyarakat, dan Sinema Orde Baru". Yogyakarta: Ombak. 2009

Thompson, Kristin \& Bordwell, David. "Film History: An Introduction, Second Edition". New York: Mc Graw-Hill. 2003. 
White, Hayden. "Historiography and Historiophoty". The American Historical Review, Vol. 93, No. 5. Desember, 1988.

Yusa Biran, Misbach. "Sejarah Film 1900-1950: Bikin Film di Jawa”. Depok: Komunitas Bambu. 2009

http://www.beyondliteracy.com/what-is-post-literacy-part-1

http://nasional.kompas.com/read/2017/09/18/23080541/panglima-tni-nilai-pemutaranfilm-g30spki-penting-untuk-generasi-muda

http://nasional.kompas.com/read/2017/10/04/18140071/jusuf-kalla-indonesia-banyakkekurangan-tak-perlu-ribut-film-dan-senjata 